AVERY LAFORTUNE

The Traumatized Time-Traveller: Locating Memory, Nostalgia and Healing in Starz' Outlander 


\section{AVERY LAFORTUNE The Traumatized Time-Traveller: Locating Memory, Nostalgia and Healing in Starz' Outlander}

Trigger warning: discussion of rape.

Every television series must establish the guiding principles of time and space within the realm of the fiction. These norms are often quickly established through the pilot episode which, according to Jason Mittell, teaches viewers how to watch the show. ${ }^{1}$ The established norms are reinforced in subsequent episodes creating a familiar status quo, one that audiences not only associate with the particular series but come to expect. Therefore, when Starz' Outlander aired the season five finale featuring vignettes located in an abstracted, imagined space, it demonstrated a clear departure from the series' usual commitment to historical realism. Based on the novels by Diana Gabaldon, Outlander tells the story of Claire Fraser (Catriona Balfe), an independent, self-assured, modern English woman who can travel through time. Claire moves back and forth between the twentieth century, her "natural" time when she was born and raised and the eighteenth century where she falls in love with Jamie Fraser (Sam Heughan). The convoluted timeline of Outlander offers direct comparison between visions of a distant past (the 1700s) and a more recent past (the 1900s). The cultural dissonance between the two time periods often provides moments of lighthearted comedy as well as more sobering social commentary particularly regarding gender norms. Although themes of time and trauma are central to the series as a whole, the expression of these ideas in the finale "Never My Love" stands apart from the series' habitual structure.

Claire's reality in "Never My Love" is located in rural North Carolina in the Autumn of 1772 while the series of surreal vignettes or "dreamscape" as it is called by the showrunners, offers an abstracted 1960s domestic setting. ${ }^{2}$ The relationship between the in-show reality and the dreamscape raises questions about how cinematic spaces are visually constructed using combinations of history, memory, reality and fiction. In other words, how does Outlander externalize time? This essay examines how episode 5:12 "Never My 
Love" constructs a space that simultaneously exists outside the bounds of linear time but is also directly informed by memory rooted in an identifiable time. I ask how this type of space serves characters and viewers alike, revealing in the process the ways in which nostalgic atemporal space functions as a trauma response and potential site of healing.

"Never My Love" picks up from the "cliffhanging" final action of the previous episode when Claire is abducted from her home by a gang of violent men angered by her attempts to educate local women about contraception. Claire's medical knowledge and opinions surrounding female agency-evidence of her twentieth-century life - were interpreted by the men as "spreading dangerous ideas, telling women how to deceive their husbands, how to deny them their God-given rights."3 "Never My Love" follows Claire's experience as captive transported through the Carolina wilderness. She is bound, beaten and repeatedly raped before eventually being rescued by Jamie and his companions. "Never My Love" is a creative outlier not because of the plot (rape is all-too prevalent in the Outlander world), but due to the way trauma is visually depicted. The episode does not rely on gratuitous violence but rather an extreme disorienting nonlinearity of scenes that blur the distinction between the real and the imagined as well as dissolving delineations between past, present and future. Rather than show the assault, viewers are relocated to a non-place/time that is at once new and strange yet instantly recognizable.

The spatial/temporal relocation is framed as a dissociation, a maladaptive coping mechanism Claire employs, allowing her to temporarily separate from the overwhelming trauma of her reality. According to the DSM-5, "dissociative disorders are characterized by a disruption of and/or discontinuity in the normal integration of consciousness, memory, identity, emotion, perception, body representation, motor control, and behaviour." Claire's experience of dissociation is communicated through a series of surreal scenes. These scenes take place in an alternative space marked by a drastic change in colour palette, mood, and temporality. The dreamscape is posited as a temporary coping mechanism, a strategy that has yet to be demonstrated in the series. The dissociative dreamscape is distinct from a flashback. In 2:9 "Je Suis Prest," a series of flashbacks were used to draw parallels between Claire's experience serving as a combat nurse in WWII (1939-45) and preparing for the battle of Prestonpans (1745). Claire's flashbacks were shown as uncontrollable, intrusive memories prompted by auditory or visual triggers. Alternatively, the dreamscape is framed as a protective measure to distance her mind from the trauma of the present. While it is constructed through an amalgamation of remembered things, it is not an actual memory.

In her mind, Glaire retreats to a place that takes the form of a mid-century modern home with the aesthetic trappings of late-1960s middle-class America. In these scenes, Claire shares a quiet moment with her husband before welcoming their extended family - all of whom strictly exist in the 1700s - into the home and sitting down for Thanksgiving dinner. The scenes clearly associate the 1960s as a time of warmth and safety securely rooted in traditional family values and the comforts of ritual — a stark contrast to the horrors she endures in the eighteenth century. Although clearly a nostalgic portrayal of the 1960s, Claire's status as a temporally displaced person complicates the orientation of the yearning. In the context of her life in 1772, Claire's personal past technically exists in the future. Therefore, for most characters within the show, this vision of the 1960s represent a forward-looking nostalgia of something yet to come. For viewers in 2020 and beyond, it presents a backward-looking nostalgia of a romanticized moment in the past. The dreamscape demonstrates a new strategy the show employs to engage with the past using nostalgia to mobilize memory and history and reveal nostalgia's "therapeutic potential."5

The episode begins with time ruptured into three distinct threads: the recent past, the present 
and the dreamscape which is at once past, present, future and atemporal. The recent past recounts significant moments leading up to the abduction as well as Claire's early experiences as hostage. The present shows Claire in a forest being abused by her captors. Meanwhile, the dreamscape incorporates her eighteenth-century family into her memories of the 1960s. While contextual and visual clues point to a specific year (1968), the events of the dreamscape are impossible according to the inner logic of the story. This vision of 1968 is framed as a subjective memory infused with imagination, gaps, and inconsistencies. Scenes from each thread of time are abruptly juxtaposed in disconcerting and disorienting fashion. Even within the dreamscape, the events of the evening are shown out of order and moments of heightened significance are looped, replaying multiple times. As Claire's traumatic experience is resolved, so too is the orientation of time until it eventually resumes an ordered, linear storytelling structure firmly rooted within the preestablished norms of the show. ${ }^{6}$

For Gabriel Pagnoni Berns and Leonard G.A. Lando, Glaire's travels through time in earlier seasons challenge the male-privileging hegemonic model of time as singular, universal and linear, supporting instead Victoria Browne's notion of feminist polytemporality. ${ }^{7}$ In this moment of extreme gendered violence, Claire does not simply challenge but completely rejects the patriarchally-imposed constraints of linear time by creating an alternative temporality to protect herself from her male captors. Although Claire never self-identifies as a feminist (despite so many of her problems stemming from issues of gender equality), her experience is testament to the existence and value of polytemporality which allows for more diverse experience and processing of time. ${ }^{8}$

Claire's journey can also be understood as a deviation from the normative straight line described by Sara Ahmed in regard to the temporality of orientation in queer phenomenology. ${ }^{9}$ In this case, Claire deviates from linear time and thus the normative sequence of life, casting her as a potential queer subject. Ahmed argues that "risking departure from the straight and narrow, makes new futures possible, which might involve going astray, getting lost, or even becoming queer." ${ }^{10}$ Although Claire steadfastly orients herself around objects of heteronormativity (her marriage to Jamie, reproduction and family lineage), the device of the dreamscape not only demonstrates but makes possible alternative ways of being. Instead of existing on a timeline where the future is ahead and the past is behind, Claire moves off the line, perhaps taking a step to the side, existing in a new present, one that could only be made possible by this deviance. This is not to say that queer bodies must be relegated to alternative or abstracted spaces and especially not at the expense of mainstream inclusivity. ${ }^{11}$ Instead, I highlight the positive potential of these spaces as possible sites of resistance and healing for these bodies.

"Never My Love" opens with a series of short, abrupt clips of the recent past, each punctuated with a sinister drum beat. The clips function as a recap of events, a standard practice at the beginning of many serialized shows including Outlander; however, the "skip" button is noticeably absent. This is not an optional synopsis but the beginning of the episode. These memories are mandatory viewing. Scenes of scruffy men on horseback, malevolent looks, shadowy interiors of a clapboard house, and a violent struggle suddenly cut to black. The title sequence is expected to play here but it is instead moved to the end of the episode. This strategy is not only thematically relevant, emphasising the disruption of sequence within the broader structure of the show, but also gives viewers a more visceral experience of disorientation by subverting long-established patterns. This unexpected break from the traditional episode format denies viewers the comfort of routine. Discarding convention creates an uneasiness, leaving viewers uncertain of what they are to experience throughout this episode. This sentiment mirrors Claire's onscreen experience of being suddenly ripped away from the comforts of her domestic routines and plunged into a dangerous situation that threatens her own future. 
Instead of playing the title sequence, the darkness cuts to a brightly lit close-up of Claire's hands, which are identifiable through her wedding rings but rendered strange from the bright red polish on her nails. Her hands calmly go through the motions of starting a record player. Association's "Never My Love" (1967) plays over establishing shots of a mid-century modern home. Viewers are treated to an influx of nostalgia fuel: a typewriter, a large boxy television, clean, geometric furniture, matching floor and ceiling hardwood. This set follows a key characteristic of screened nostalgia described by Christine Sprengler who notes: "its triggers are primarily visual in nature and derive from a canon of symbolic material objects, visual tropes and visual styles associated with media representations of the past." 12 The entire house and its contents are overlaid in Pantone colours that instantly evoke late 1960s/early 1970s America including hues of harvest gold, burnt sienna, rust, and avocado. The bright, warm, highly-saturated colours of the house contrast the dark, cool, natural tones of Claire's reality - underscoring the difference in temporality. The opposing colour palettes demonstrate a cinematic strategy that mobilizes colour-memory deeply connected to historical, cultural and personal recollections to evoke the feeling of a specific time. ${ }^{13}$ The home's large windows and rectangular spaces recall the designs of Frank Lloyd Wright or, considering the show is filming Scotland for North Carolina, Peter Womersley.

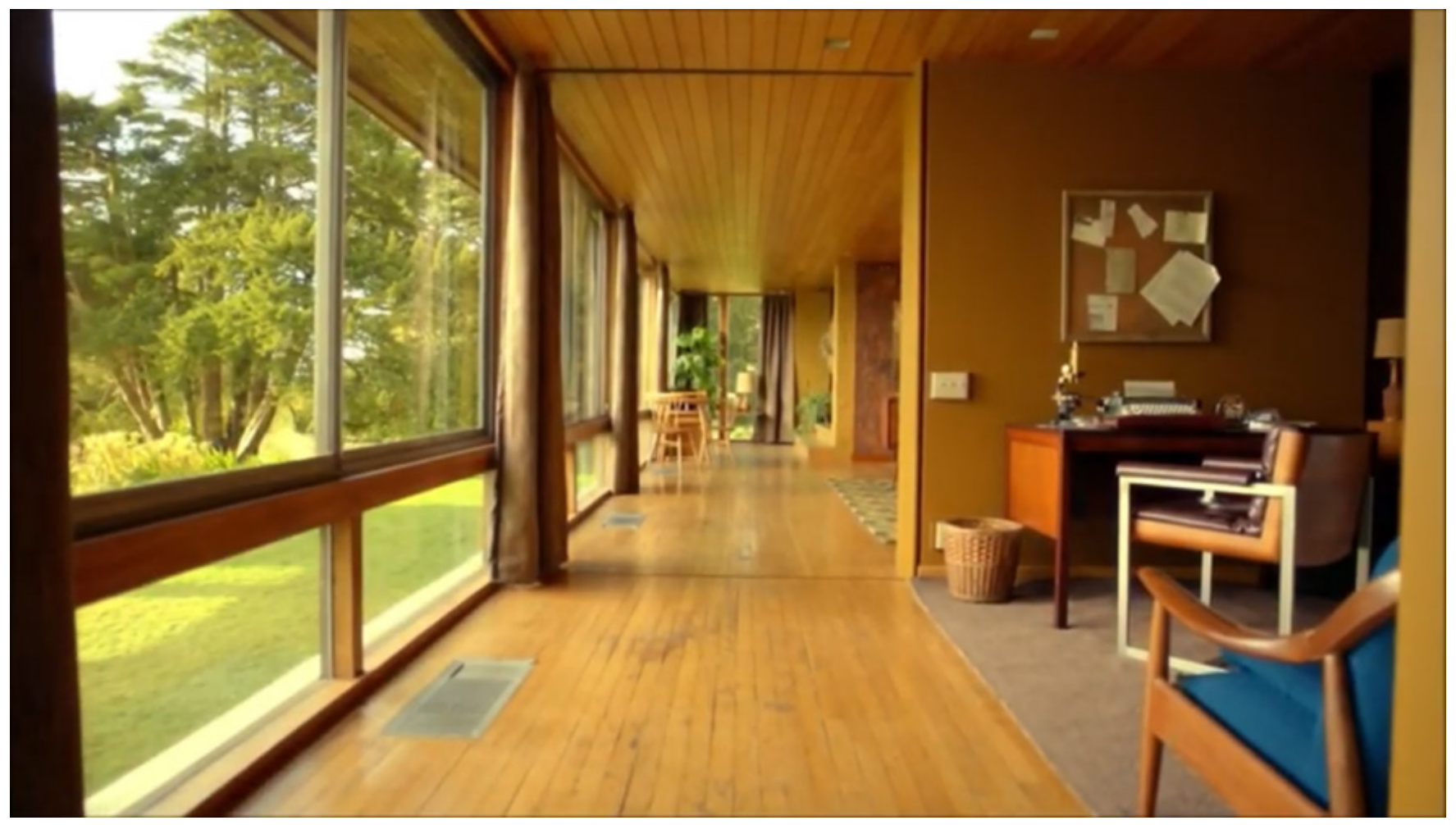

Figure 1. Establishing shot of the dreamscape house. Screenshot, "Never My Love,” Outlander (2020), Starz. 
Claire sits on the couch. Her excessively hairsprayed smooth bob and bright red sheath dress immediately distance her from the natural hairstyling and organically-dyed homespun of the eighteenth century. Carrying connotations of technological advancement, social freedoms and sexual liberation, the sheath dress embodies the sensibility of the modern setting just as the modest hemlines, stays and layers of petticoats are oppositionally cast in a regressive, oppressive light (although these same styles are clearly romanticized in other episodes). ${ }^{14}$ Viewers are reminded of the politically-charged sliding scale of "appropriateness" assigned to clothing and its symbolic function of denoting moral acceptability. Claire's comparatively conservative eighteenth-century outfit reflects the values of a more puritan society but does not protect her against the misogyny and gendered violence embedded in this culture.

Viewers have seen Claire in similarly modern outfits and settings in earlier seasons when she lived in America from 1946-1968. The material construction of her experience in the "real" 1960s is identical to this imagined 1960s. Both visions of the past feature the same reliance on canonical objects located in the material reality of the time. Viewers understand the vignettes are a product of an altered mental state through the episode's non-material communication including tonal shift and intentional discontinuity. Claire's behaviour is inconsistent with her character, rarely speaking and remaining detached from the action of the scene. Cinematographic cues blur the lines of spectator and participant, of character and audience. At times, the dreamscape is filmed through unobtrusive third person perspective (the Outlander norm); however, in one instance Claire looks towards the camera placed in the upper corner of the room. The static high-angle shot provides a detached surveillance perspective evocative of security camera footage. This impersonal, almost voyeuristic perspective, is later changed to a point of view shot where we, the viewer, are intimately involved in the scene. Seeing from Claire's perspective, her daughter-in-law Marsali (Lauren Lyle) looks into the lens, holds up her infant daughter and makes her wave to the camera, to us. Viewers are both within the scene and without it. We watch Claire and we are Claire in the same way that Claire is simultaneously present and not present in her own body.

The different treatment given to her imagined return versus her literal return to the twentieth century creates the implicit (or explicit) assumption that some representations of the past are more real than others. This idea is reinforced when executive producer/writer Matthew B. Roberts refers to scenes of Claire's present-day as "reality footage" to distinguish it from the dreamscape. ${ }^{15}$ Engaging in historical fiction necessitates a balance of real and imagined as it weaves historical events, figures and customs into a fictional story. However, neither scenario provides an unmediated glimpse into the past. Claire's "reality footage" is as much a creative interpretation of the past as her dreamscape. Despite this, the showrunners appear much more reluctant to definitively situate Claire's dreamscape in real time. Executive Producer Maril Davis describes it as, "an interesting non-descript time period although one could say we kind of centered around the Sixties." 16 Roberts states: "so we started off with the Sixties and then it kind of morphed into an amorphous time that doesn't really have a period." 17 While the dreamscape features anachronism that complicates viewers' ability to locate its temporality, the house design, decoration and costumes provide information that encourages viewers to locate the fantasy in a real time. A "non-descript time period" would either be void of markers of time or feature enough contradictory signifiers to deny the possibility of locating a single, identifiable moment. Instead, the dreamscape's material objects as well as the context of Claire's life clearly point to a moment around 1968. Although time is no longer established through the linear sequence of events, it is established materially and spatially. Time and its connotations exist in the material culture worn on her body and shaping her surroundings. The house is built from the representational hallmarks of a specific moment in American history. In this context, space is time. 


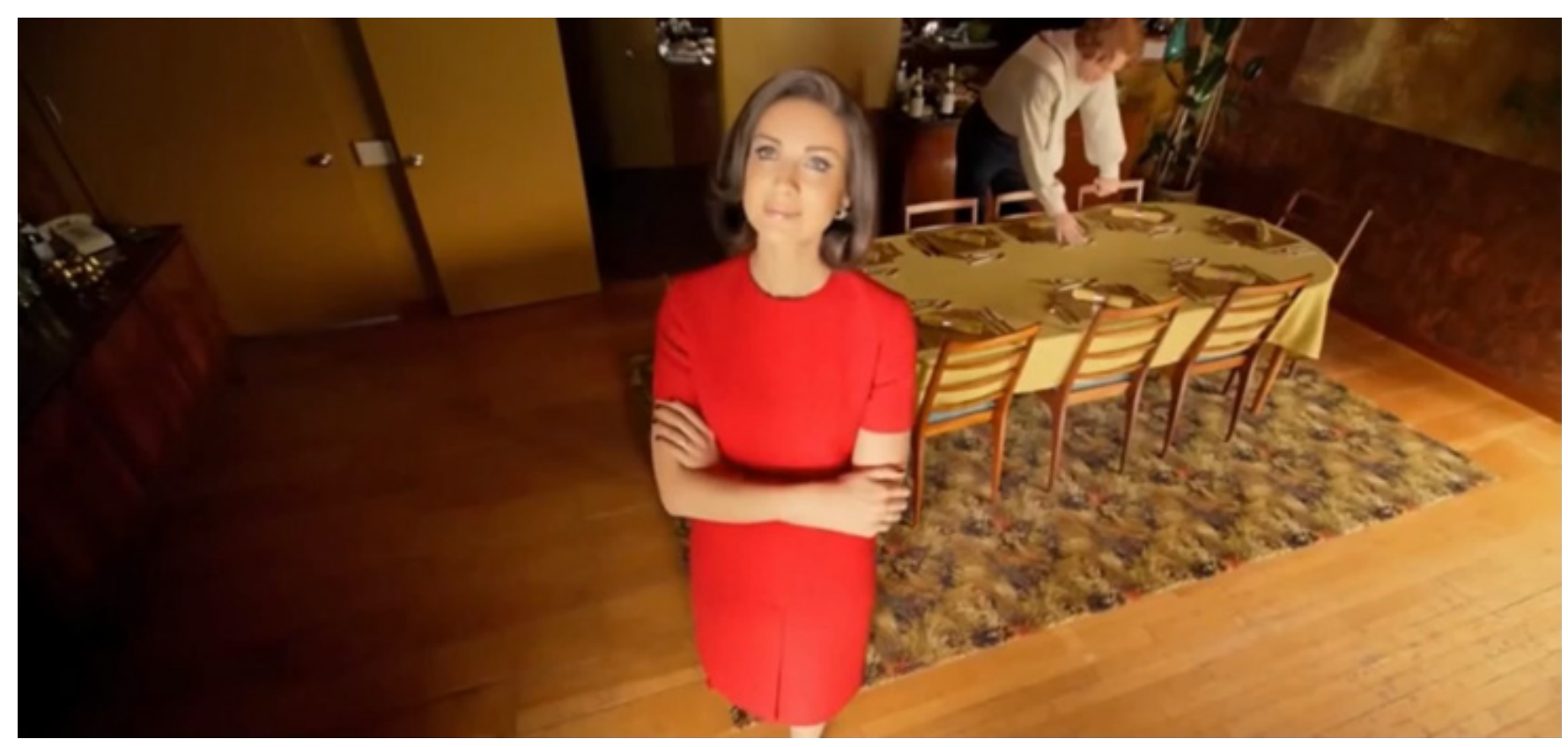

Figure 2. Claire notices a leak in the roof (Jamie sets the table for dinner). Screenshot, "Never My Love," Outlander (2020), Starz.

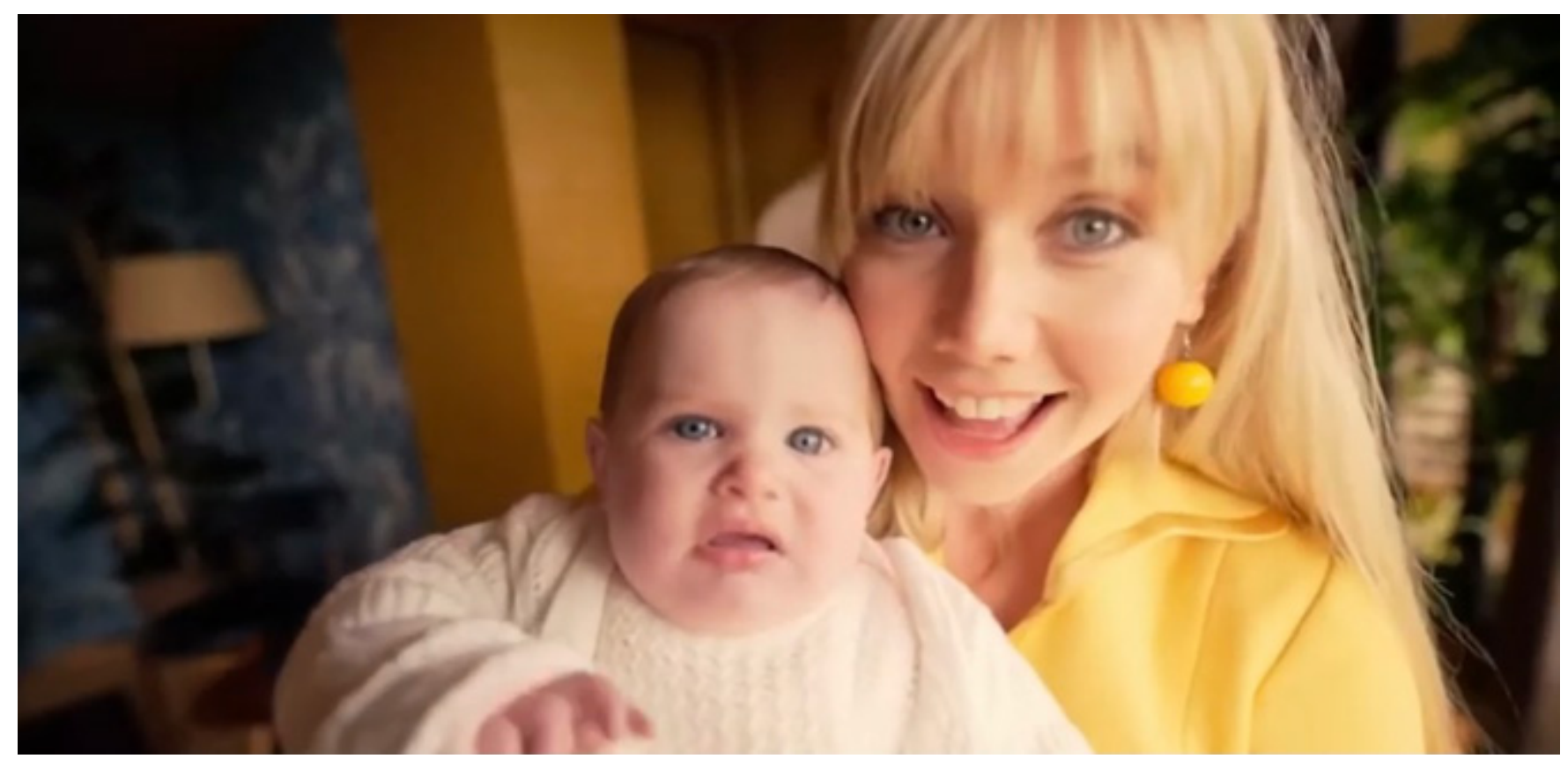

Figure 3. Marsali engages with the point of view shot. Screenshot, "Never My Love," Outlander (2020), Starz. 
The dreamscape is very consciously constructed from the reality of the show as well as viewers' understanding of the 1960s (or at least the 1960s that exists in popular media). The house is not random. It was introduced in the title card of 5:5 "Perpetual Adoration." In a brief callback to Claire's earlier life, the title card shows her picking up an April 1968 edition of Modern Building Review magazine featuring the home on its cover. The show deliberately plants the house in Claire's and viewers' minds to be recalled later. The key difference between Claire's literal and imagined returns seems to lie in the nostalgic lens overlaid onto the dreamscape which is unselfconscious in its invention. Nostalgia, a combination of the Greek nostos (return home) and algos (pain) was originally understood as a type of severe homesickness, but today evokes broader sentiments of longing for a time or place that may or may not have truly existed. Although linked to memory and the act of remembering, nostalgia is often infused with fantasy or heavy romanticization. Claire's nostalgic yearning for home - in this case, not just the idea of a place of belonging but quite literally the physical structure and sanctuary of a house - makes room for nostalgia's tendency to overtly invent or reinvent in a way that Claire's "real" experiences of the past do not. The dreamscape can also be understood within the conventions of the fantasy genre, which locates the imagined within a space that is superficially fictional yet immediately recognizable. Using the 1960s as the backdrop for unreal events is no less anachronistic than high fantasy's tendency to adopt a medieval setting to situate magic and myth. Although some fictions appear to be more fictitious than others, they all have ties to reality while scenes of reality are all, to varying degrees, fictitious.

Situating the dreamscape in a descript time implicates the sensibilities and connotations of that time, ideas that are largely shaped and perpetuated by visual culture. "Never My Love" plays off of and reinscribes pre-existing pop culture characterization of time that present the distant past as a place of constant violent misogyny and the 1960s as a charming familial utopia. The romanticised comfort of 1960s domesticity is as familiar to audiences as the ever-present threat of rape and victimization in apparently any period of Western history before the feminist first wave, both of which are inherently flawed. The prevalence of rape and gendered violence in historically-inspired stories has become increasingly controversial as pop-culture juggernauts like Game of Thrones are charged with an overreliance on gratuitous sexual violence. ${ }^{18}$

Although Outlander was initially praised for its sensitive handling of Jamie's rape in season one, sexual violence has become increasingly relied upon to stimulate character arcs. ${ }^{19}$ Everyone in the central family has now experienced horrific rapes not to mention those of secondary characters, the near-constant threat of rape and several encounters of questionable consent. ${ }^{20}$ Claire is raped just two episodes after the final conclusion of her daughter Brianna's (Sophie Skelton) assault-driven plotline. This ensures that viewers cannot, for one moment, forget that the distant past is no place for a woman (despite women having lived fulfilling and accomplished lives for thousands of years). Although visions of the past need to acknowledge female agency and power, the gendering of History and current pop culture norms as evidenced by this episode further underscores the importance of creating space outside the confines of hegemonic time. Viewers, especially female viewers, deserve quality escapism that does not reduce them to targets of sexual violence.

Although achieved through different mechanisms, the function of Claire's imagined and literal returns to the twentieth century are the same: they provide an escape from the dangers of the eighteenth century. ${ }^{21}$ However, the benefit of the imagined return is that it allows for the creation of a setting that is more desirable than the reality of the past (future). Claire's actual experience of the 1960s was rife with sexism (particularly in the workplace as a female physician), chronic loneliness and the tumultuous dissolution of her marriage to Frank Randall (Tobias Menzies). When given the opportunity, she chose to leave 
1968 to return to the eighteenth century. Instead of recreating her "actual" experience of the 1960s for the dreamscape, Claire draws upon its material comforts and the general political progressiveness she associates with the time to inform her dissociation (somewhat ironic given its role in second wave feminism belying a deficiency of progressiveness). Claire's relationship with time is significantly altered by the extreme conditions of her present, which require her to deliberately and effectively reinvent her past to better serve her in the moment. Her escape is completely contained within the insular structure of the home, ignoring outer society. Comfort is derived from the home, its domestic objects and her family interacting within the space. It is when the outside world creeps in via a leak in the roof, a face in the window, police officers at the door, that the dreamscape begins to collapse. The fiction of her vision of 1968 is essential to its success as a coping mechanism. Therefore, nostalgia is not merely a symptom of her trauma but a productive tool for survival. ${ }^{22}$

Trauma necessitates nostalgia. Robert Hemmings notes that, "not only do nostalgia and trauma operate from the same liminal space between memory and forgetting, but also that they are often similarly rooted in the experience of war, and more particularly, the experience of surviving war." 23 Instead of regressing to a simpler time of "before" (i.e. before the war), Claire yearns for the "after," a future of increased personal freedom and gender equality. Pagnoni Berns and Lando articulate the tension of Claire's temporal displacement, "When Claire is transported to the year 1743, she ends up losing any gain made by feminism...she cannot live properly in an era in which women are properties of men after living in an era with a more progressive agenda." 24 Claire's nostalgia is not a reactionary anxiety response to social acceleration or the unrepeatability (loss) inherent to conceptualizing time as linear. Claire craves the freedom and relative safety that she knows will eventually come. Claire's nostalgia demonstrates an inversion of the (predominantly male) longing for pre-industrial pastoral romanticism. As she lays incapacitated on the forest floor, far removed from the safety of civilization, Claire dreams of a time that might at first seem a strange utopia due to its proximity to the chaos of World War II, but ultimately exists as the most progressive society she has known. Claire's particular brand of nostalgia is firmly rooted in her identity as a time traveller and as a woman.

The healing potential of Claire's imagined space lies not only in its escapism but also its ability to facilitate the investigation and processing of complex memory. Kerwin Klein offers memory as a "therapeutic alternative to historical discourse." ${ }^{25}$ The dreamscape provides an environment to explore this form of therapy. Viewers are presented with a multilayered past that engages with the history of the series as well as real-world collective memories and histories. After five seasons, ample in-show history has been established for the writers to draw from viewers' long-term memory, bringing it to the forefront of their working memory in order to inform their comprehension of the current on-screen happenings. ${ }^{26}$

In-show memories are evoked through recycled dialogue and material references or "Easter eggs." "27 These references are not informational recaps of events but memory triggers that bring the past into the present. ${ }^{28}$ When Jamie wraps a blanket around Claire saying, "You're shaking so hard it's making my teeth rattle," he is repeating his dialogue and blocking from the pilot episode "Sassenach." It recalls the time when he and Claire first meet and begin to trust one another. The similarities create an odd sense of déjà vu. The past is reimagined and recontextualized, effectively challenging delineations between imagination and history while emphasizing the thematic relevancy of the past within the present. The blocking is repeated once more in "real time" when Jamie rescues Claire and wraps her in his plaid, once again underscoring the comfort and safety provided by their relationship. More in-show memories are referenced through objects. A painting, an orange, and a vase are introduced in the initial establishing shots. Each object fits within the domestic setting, but savvy viewers will connect these symbols to earlier episodes and subsequent themes of home, trauma and survival. ${ }^{29}$ 
Personal and national memory intersect when Claire's grandson Germain (Robin Scott) runs into the arms of Jamie's godfather Murtagh (Duncan Lacroix) who jokes, "It's Prestonpans all over again!" This callback references the Battle of Prestonpans which exists doubly as an in-show memory from season two and an historical memory of a significant Jacobite victory during the Jacobite Rising of $1745 .{ }^{30}$ The events of the Rising feature prominently in seasons one and two and mark a pivotal moment in the formation of Scotland's national and cultural identity. Early victories like Prestonpans eventually culminated in a massive defeat at the Battle of Culloden. Afterwards, a Crown-sanctioned genocide of the Scots in retribution for the rising effectively ended Highland clan culture. The reverberations of this trauma continue to be felt today throughout the Scottish diaspora. The Jacobite future was destroyed at Culloden but Prestonpans remains an oft-nostalgized ${ }^{31}$ time when their dream of a different future (a restored Catholic monarchy) seemed not only within reach but imminent. This moment in Claire's vision illustrates Svetlana Boym's notion that, "nostalgia is about the relationship between individual biography and the biography of groups or nations, between personal and collective memory." ${ }^{22}$ Murtagh and Jamie, through whom the viewers "experience" the events of the Rising, were, like many Highlanders, permanently scarred from the experience. In Claire's imagined nostalgic space, Murtagh achieves enough temporal distance from the rising to be able to reference Prestonpans in this lighthearted fashion, something he could never do during his lifetime. This alternative space not only promotes Claire's own healing but also that of her family (including members whose physical ailments are also healed in her vision). Furthermore, by recalling a valuable moment of Highland pride, this scene encourages broader cultural healing through acknowledgment and remembrance. More than survival, this is a space where harm can be undone.

"Never My Love" provides a rich case study in the politics of constructing time and place. Objects of material culture exist as physical embodiments of time that both represent and inform our understanding of when they are from. The relationship between time, non-time and material culture is wrapped up in nostalgic construction as Boym articulates, "the object of romantic nostalgia must be beyond the present space of experience, somewhere in the twilight of the past or on the island of utopia where time has happily stopped, as on an antique clock." 33 The experience of time is inherently traumatic. This is evidenced by Claire's harrowing journeys through time, the violent splicing of time at the beginning of the episode as well as more general experiences of suffering, survival and endurance. The concept of linear time is intrinsically linked with colonial and patriarchal notions of progress, human advancement and rationality and "negates the possibility of alterity." 34 It therefore stands to reason that spaces for healing from oppressive systems are most productive when they exist outside the bounds of linear time. Alternative and multiple temporalities provide a kind of relief that is at once soothing, productive and essential. Healing nostalgic spaces appear to be on the rise in mainstream television, most recently playing a central role in Disney's Wandavision. Initially conceptualized as a disease, nostalgia is now being employed as a viable remedy delivered through visual media. Claire's escape from the anxieties of her present reality in favour of a more comfortable imagined space is familiar to viewers as it mirrors the function of television itself. 


\section{Endnotes}

1 Jason Mittell, Complex TV: the Poetics of Contemporary Television Storytelling (New York: New York University Press, 2015), 57.

2 "Inside the World of Outlander | Season 5 Finale | STARZ" STARZ, Video, May 12, 2020, https://www. youtube.com/watch?v=Hkd0Dw2LXlk.

3 It is notable that the TV show changes the motivation of the abduction from a theft gone wrong (as it is characterized in the book) to a retaliation against female sexual education and the autonomy of contraception.

4 American Psychiatric Association, "Dissociative Disorders," in Diagnostic and Statistical Manual of Mental Disorders, $5^{\text {th }}$, ed. (Arlington, VA: American Psychiatric Publishing, 2013), https://doi-org.proxy1.lib.uwo. ca/10.1176/appi.books.9780890425596.dsm08.

$5 \quad$ Christine Sprengler, Screening Nostalgia: Populuxe props and technicolor aesthetics in contemporary American Film (New York: Berghahn Books, 2009), 32.

6 To clarify, although the series moves back and forth through time, the vast majority of the story unfolds through a linear sequence of events (barring the odd flashback as previously discussed). The unusual nature of the non-linearity in "Never My Love" lies in the jumbled order or looping of events and travelling to a time that is neither forward nor backward but elsewhere.

$7 \quad$ Fernando Gabriel Pagnoni Berns and Leonardo G.A. Lando, "Reviewing Linear Time: History Repeating All Over Again (Now, Against You)," in Outlander's Sassenachs: Essays on Gender, Race, Orientation and the Other in the Novels and Television Series, ed. Valerie Estelle Frankel (Jefferson, NC: McFarland \& Company, 2016), 112.

8 This relates back to feminist discourse on the gendering of history and "grand narratives" of a universal world history. Victoria Browne, Feminism, Time and Nonlinear History (New York: Palgrave, 2014), 10.

9 Sara Ahmed, "Orientations: Toward a Queer Phenomenology," GLQ: A Journal of Lesbian and Gay Studies vol. 12 no. 4 (2006): 554. See also the discussion of the bodily horizon and alignment of straight lines, 562.

10 Ahmed, "Orientations," 554.

11 Ahmed, "Orientations," 565, see also 568-9.

12 Sprengler, Screening Nostalgia, 33.

13 Ute Holl, "Nostalgia, Tinted Memories and Cinematic Historiography: On Otto Preminger's Bonjour Tristesse (1958)," in Media and Nostalgia: Yearning for the Past, Present and Future, ed. Katharina Niemeyer (London: Palgrave Macmillan UK, 2014), 161.

14 For an in-depth look at the sheath dress and its broader social and political implications in 1960s American culture both onscreen and off see Meenasarani Linde Murugan, "Maidenform: Temporalities of Fashion, Femininity, and Feminism," in Analyzing Mad Men: Critical Essays on the Series, ed. Scott F. Stoddart (Jef ferson, NC: McFarland \& Company, 2011), 166-185.

15 Matthew Roberts, "Outlander: Episode 512 Podcast 'Never My Love," Outlander: The Official Podcast, May 13, 2020, accessed March 30, 2021, https://podcasts.apple.com/ca/podcast/outlanderepisode-512-podcast-never-my-love/id910631883?i=1000474635523.

16 "Inside the World of Outlander | Season 5 Finale | STARZ" STARZ, Video, May 12, 2020, https://www. youtube.com/watch?v=Hkd0Dw2LXlk.

17 "Outlander | Behind the Season 5 Finale | STARZ" STARZ, Video, May 11, 2020, https://www.youtube. $\mathrm{com} /$ watch? $\mathrm{v}=\mathrm{lx} 8 \mathrm{WknFxdVM}$.

18 See Dave Itzkoff, “For 'Game of Thrones,' Rising Unease Over Rape's Recurring Role,” in The New York Times, May 2, 2014, https://www.nytimes.com/2014/05/03/arts/television/for-game-of-thrones-risingunease-over-rapes-recurring-role.html.

19 Byrne and Taddeo discuss the sympathetic fan response to the depiction of Jamie's rape in season one. Katherine Byrne and Julie Anne Taddeo, "Calling \#TimesUp on the TV period drama rape narrative," in Critical Studies in Television: The international Journal of Television Studies, vol. 14, no. 3 (2019): 389.

20 Both Game of Thrones and Outlander are adaptations giving the added excuse of defending the presence 
of sexual violence because it exists in the source material. In these instances, the curatorial role of the show runners is often downplayed as though they are powerless when it comes to determining which events make it into their scripts.

21 The danger that motivated her first escape from the eighteenth century was the Battle of Culloden com bined with a high-risk pregnancy that required more advanced medical attention than what she could expect from 1746.

22 Svetlana Boym also recognized nostalgia as a survival mechanism in relation to displaced people "making sense of the impossibility of homecoming." Svetlana Boym, The Future of Nostalgia (New York: Basic Books, 2001), xvii.

23 For many women, the "experience of war" is the type of assault Claire experiences. Rape is often used as a weapon of war. Robert Hemmings, Modern Nostalgia: Siegried Sassoon, Trauma and the Second World War (Edinburgh: Edinburgh University Press, 2008), 3.

24 Pagnoni Berns and Lando, "Reviewing Linear Time," 108.

25 Kerwin Lee Klein, From History to Theory (Berkeley: University of California Press, 2011), 137.

26 Mittell, Complex TV, 182.

27 The popular term for hidden messages in film and television that cater to fan culture.

28 Mittell, Complex TV, 182-3.

29 The painting depicts an abstract of their current home, the orange calls back to an assault Claire experienced in 2:7 "Faith" and the vase is an ongoing symbol of Claire's desire to establish a home that was first introduced in the pilot episode "Sassenach."

30 For a more focused look on the relationship between the history of Culloden and Outlander see Sandi Solis, "Culloden and Wounded Knee: Genocide, Identity and Cultural Survival," in Outlander's Sassenachs: Essays on Gender, Race, Orientation and the Other in the Novels and Television Series, ed. Valerie Estelle Frankel (Jefferson, NC: McFarland \& Company, 2016): 17-30.

31 Here I use nostalgia as a verb to emphasize the active process as something that is done rather than felt or relating to a state of being. Katharina Niemeyer, "Introduction," 10.

32 Boym, The Future of Nostalgia, xvi.

33 Ibid, 13.

34 Pagnoni Berns and Lando, "Reviewing Linear Time," 108. 


\section{Bibliography}

Ahmed, Sara. "Orientations: Toward a Queer Phenomenology." GLQ: A Journal of Lesbian and Gay Studies vol. 14 no. 4 (2006): 543-574.

American Psychiatric Association. "Dissociative Disorders." In Diagnostic and Statistical Manual of Mental Disorders, 5th ed. Arlington, VA: American Psychiatric Publishing, 2013. https://doi-org. proxy1.lib.uwo.ca/10.1176/appi.books.97808 90425596.dsm08

Boym, Svetlana. The Future of Nostalgia. New York: Basic Books, 2001.

Browne, Victoria. Feminism, Time and Nonlinear History. New York: Palgrave, 2014.

Byrne, Katherine and Julie Anne Taddeo. "Calling \#TimesUp on the TV Period Drama Rape Narrative." Critical Studies in Television: The International Journal of Television Studies vol. 14, no. 3 (2019): 379-398.

Hemmings, Robert. Modern Nostalgia: Siegried Sassoon, Trauma and the Second World War. Edinburgh: Edinburgh University Press, 2008.

Holl, Ute. "Nostalgia, Tinted Memories and Cinematic Historiography: On Otto Preminger's Bonjour Tristesse (1958)." In Media and Nostalgia: Yearning for the Past, Present and Future. Edited by Katharina Niemeyer, 160-175. London: Palgrave Macmillan UK, 2014.

"Inside the World of Outlander | Season 5 Finale STARZ." STARZ. Video. May 12, 2020. https:// www.youtube.com/watch?v=Hkd0Dw2LXlk.

Itzkoff, David. 'For 'Game of Thrones,' Rising Unease Over Rape's Recurring Role." In The New York Times. May 2, 2014. https://www.nytimes. $\mathrm{com} / 2014 / 05 / 03 /$ arts/television/for-game-ofthrones-rising-unease-over-rapes-recurring-role.html.

Klein, Kerwin Lee. From History to Theory. Berkeley: University of California Press, 2011.
Mittell, Jason. Complex TV: the Poetics of Contemporary Television Storytelling. New York: New York University Press, 2015.

Murugan, Meenasarani Linde. "Maidenform: Temporalities of Fashion, Femininity, and Feminism." In Analyzing Mad Men: Critical Essays on the Series. Edited by Scott F. Stoddart, 166-185. Jefferson, NC: McFarland \& Company, 2011.

Niemeyer, Katharina. "Introduction: Media and Nostalgia." In Media and Nostalgia: Yearning for the Past, Present and Future. Edited by Katharina Niemeyer, 1-23. London: Palgrave Macmillan UK, 2014.

"Outlander | Behind the Season 5 Finale | STARZ" STARZ. Video. May 11, 2020. https://www. youtube.com/watch? $\mathrm{v}=\mathrm{lx} 8 \mathrm{~W} \mathrm{knFxdVM}$.

Pagnoni Berns, Fernando Gabriel and Leonardo G.A. Lando. "Reviewing Linear Time: History Repeating All Over Again (Now, Against You)." In Outlander's Sassenachs: Essays on Gender, Race, Orientation and the Other in the Novels and Television Series. Edited by Valerie Estelle Frankel, 105-116. Jefferson, NC: McFarland \& Company, 2016.

Roberts, Matthew. "Outlander: Episode 512 Podcast 'Never My Love." Outlander: The Official Podcast. May 13, 2020. Accessed March 30, 2021. https://podcasts.apple.com/ca/podcast/ outlander-episode-512-podcast-never-my-love/ id910631883? $\mathrm{i}=1000474635523$.

Solis, Sandi. "Culloden and Wounded Knee: Genocide, Identity and Cultural Survival." In Outlander's Sassenachs: Essays on Gender, Race, Orientation and the Other in the Novels and Television Series. Edited by Valerie Estelle Frankel, 17-30. Jefferson, NC: McFarland \& Company, 2016.

Sprengler, Christine. Screening Nostalgia: Populuxe Props and Technicolor Aesthetics in Contemporary American Film. New York: Berghahn Books, 2009. 